\title{
Educação à Distância e Docência no Ensino Superior: Mudança de Paradigma Através da Utilização das Tecnologias no Processo de Ensino e Aprendizagem em Tempos de Pandemia da Covid 19
}

\author{
Josiane Lima Mendes ${ }^{1}$; Eliza Angélica Rodrigues Ponte² ; Léa Barbosa de Sousa ${ }^{3}$; \\ Cynira Kezia Rodrigues Ponte Sampaio ${ }^{4}$; Nayara Machado Melo Ponte ${ }^{5}$
}

\begin{abstract}
Resumo: A Educação a distância é a modalidade de ensino que mais cresce na contemporaneidade, parte desse crescimento é consequência do desenvolvimento das tecnologias de informação e comunicação - TICs. O aumento da procura por esse modelo de ensino é devido as vantagens que ele oferece, dentre essas podemos destacar a liberdade dos horários de estudo e a possibilidade de estudar em casa, o que possibilita a formação para os indivíduos que trabalham ou residem longe dos centros universitários. Partindo do exposto, esse artigo tem como objetivo discutir a mudança de paradigmas do ensino a distância durante a pandemia da Covid 19, A metodologia adotada para a realização desse estudo foi a pesquisa bibliográfica em bases de dados cientificas e com documentos oficiais que tratam do tema. Nas considerações finais aponta-se caminhos para pensar os rumos da $\mathrm{EaD}$, durante e pós pandemia, afinal, com a pandemia do COVID 19 o cenário educativo teve que redefinir seus paradigmas e excluíram algumas ressalvas e preconceitos existentes com relação a modalidade $\mathrm{EaD}$.
\end{abstract}

Palavras-chave: Educação a Distância. Tecnologia. Pandemia.

\footnotetext{
${ }^{1}$ Graduação em Farmácia e Mestrado em Ciências Biotecnológicas pelo Centro Universitário Inta - UNINTA . Especialização em Saúde da Família e Farmácia Clínica e Prescrição Farmacêutica. Coordenadora do Curso de Farmácia EAD-UNINTA, Diretora Pedagógica do Semi-Presencial. Sobral-Ceará. Josifarma0702@gmail.com;

${ }^{2}$ Graduação em História pela Faculdade de Filosofia Dom José de Sobral. Graduação em Teologia pela Faculdade de Educação Tecnológica e Graduação em Pedagogia pela Universidade Estadual Vale do Acaraú. Especialização em Magistério em $1^{\circ}$ Grau pela Universidade Estadual Vale do Acaraú , Especialização em Ciências da Educação pelas Faculdades INTA e Especialização em Didática do Ensino Superior (UNINTA). Mestrado em Ciências da Educação pela Universidade Lusófona de Humanidades e Tecnologias, ULHT, Portugal, onde também cursa o Doutorado no mesmo Programa. Pró-Reitora de PósGraduação Lato Sensu e Diretora do Centro de Humanas e Exatas do Centro Universitário INTA - UNINTA. elizaangeica@uninta.edu.br;

${ }^{3}$ Pedagoga pela Universidade Estadual Vale do Acaraú . Especialização em PSICOPEDAGOGIA (UVA/UNINTA). Especialização em CIÊNCIAS DA EDUCAÇÃO-UNINTA. Especialização em DIDÁTICA DO ENSINO SUPERIORUNINTA. Mestrado em Ciências da Educação e Doutoranda pela Universidade Lusófona de Humanidades e Tecnologias (ULHT/UFC). Avaliadora do Sistema Nacional de Avaliação da Educação Superior (BASis-MEC). Coordenadora da Clínica de Psicopedagogia (UNINTA). Professora de graduação e pós-graduação (UNINTA). lea-b@ hotmail.com;

${ }^{4}$ Doutoranda em Educação pela Universidade Lusófona de Humanidades e Tecnologias - Lisboa-PT. Mestra em Gestão Pública e Saúde Coletiva pela Universidade Estadual de Campinas - UNICAMP. Especialista em Saúde Pública e Vigilância Sanitária pelo Instituto Superior de Teologia Aplicada - INTA. Especialista em Gestão Pública em Saúde pela Universidade Estadual de Campinas - UNICAMP. Graduada em Medicina Veterinária pelo Instituto Superior de Teologia Aplicada - INTA (2015). Diretora Geral da FIED. Docente na Pós-Graduação Lato Sensu do Centro Universitário INTA UNINTA.ckrpsampaio@uninta.edu.br;

${ }^{5}$ Graduação em Serviço Social pelo Instituto Superior de Teologia Aplicada. Especialização em Seguridade e Serviço Social pelo Instituto Superior de Teologia Aplicada - INTA, Especialização em Educação na Saúde para Preceptores do SUS, no Hospital Sírio-Libanês. Mestre e Doutoranda em Ciências da Educação. Universidade Lusófona de Humanidades e Tecnologias, ULHT, Portugal. Diretora Geral da Faculdade Alencarina - FAL. nayarameloponte@ hotmail.com.
} 


\title{
Distance Education and Teaching in Higher Education: Changing the Paradigm Through The use of Technologies in the Teaching and Learning Process in Times of Pandemics of Covid 19
}

\begin{abstract}
Distance Education is the fastest growing modality of education nowadays, part of this growth is a consequence of the development of information and communication technologies - ICTs. The increased demand for this teaching model is due to the advantages it offers, among which we can highlight the freedom of study hours and the possibility of studying at home, which enables training for individuals who work or live far from the center's College students. Based on the above, this article aims to discuss the change in distance learning paradigms during the Covid 19 pandemic. The methodology adopted to carry out this study was the bibliographical research in scientific databases and with official documents dealing with the subject. The final considerations point out ways to think about the paths of distance education, during and after the pandemic, after all, with the COVID 19 pandemic, the educational scenario had to redefine its paradigms and excluded some existing reservations and prejudices regarding the distance education modality.
\end{abstract}

Keywords: Distance Education. Technology. Pandemic.

\section{Introdução}

Este artigo propõe discorrer sobre a educação à distância e à docência no Ensino Superior: mudança de paradigma através da utilização das tecnologias no processo de ensino e aprendizagem em tempos de pandemia da covid 19. Estamos acompanhando um cenário de mudanças significativas no que concerne à educação superior no país.

Corrêa (2020) diz que a educação é parte constituinte da sociedade humana, portanto são permeados por influências políticas, econômicas e sociais de diferentes grupos. A compreensão de educação adotada pelo pesquisador, é a educação como um "processo humanizador, permanente, pois torna-se humano a partir da relação dialética com o mundo da história e da cultura, a práxis que possibilita que o ser humano se construa enquanto participa da construção do mundo".

Analisando o cenário atual de pandemia que iniciou no Brasil em meados de março de 2020 pode-se observar as consequências a curto, médio e longo prazo, além de mudar o cotidiano das pessoas, afetou drasticamente a economia, a política e a educação A educação, assim como diversos outros setores, tiveram que se reinventar nesse momento, pois o isolamento não significa ausência das aulas. Dessa maneira, encontrou no ensino remoto uma forma de minimizar os danos causados pela pandemia na educação.

No dia 17 de março de 2020, o MEC através da portaria $n^{\circ} 343$, determinou sobre a substituição das aulas presenciais por aulas remotas no período pandêmico. A legalização do 
ensino remoto pelo Conselho Nacional de Educação (CNE), ocorreu no dia 28 de abril de 2020, onde orientava a reorganização do calendário escolar e instituiu a equivalência de atividades não presenciais com o fim de cumprir a carga horária mínima anual, ocasionada pela pandemia do COVID - 19 .

Diante desse contexto os setores educacionais e as Instituições de Ensino Superior (IES) que começavam a enfrentar inadimplência e cancelamento de contratos, tiveram que superar um novo obstáculo, afinal, apesar de regulamentado pelo MEC, ninguém estava preparado para o ensino remoto. Alunos, famílias, professores, instituições de ensino tiveram que reinventarse para superar os desafios do ensino remoto e nesse processo a tecnologia foi essencial para a mediação da aprendizagem.

O ensino remoto tornou-se essencial para minimizar os prejuízos na aprendizagem dos alunos e o atraso do retorno as atividades presenciais, exigindo um esforço das instituições de ensino, dos docentes, estudantes e colaboração de todos os envolvidos na educação.

Dessa maneira, este artigo está organizado em três partes, propondo reflexões sobre o contexto educacional contemporâneo e os desafios do ensino remoto para o ensino e aprendizagem.

$\mathrm{Na}$ primeira parte propomos reflexões sobre a docência no ensino superior em $\mathrm{EaD}$ e o desafios que esses profissionais têm enfrentado para garantir um ensino dinâmico e de qualidade.

$\mathrm{Na}$ segunda parte discutimos o assunto crescimento do ensino remoto no Brasil, apontando suas problemáticas e potencialidades.

$\mathrm{Na}$ terceira parte realizamos uma análise dos impactos da pandemia na educação elencando seus pontos altos e suas deficiências.

\section{Metodologia}

O desenvolvimento desse artigo adotou os procedimentos metodológicos da pesquisa bibliográfica em bases de dados cientificas tais como Scielo, BVS, Lilacs, livros de autores renomados na literatura brasileira e Pubmed, foram ainda utilizadas publicações oficiais do Ministério da educação, Ministério da saúde e publicações de instituições qualificadas que estudam e tratam sobre o tema 


\section{Ensino Remoto à Distância no Brasil}

A educação a distância é uma modalidade de ensino que tem como principal objetivo o processo educacional onde professor e aluno se encontram no espaço físico virtual diferente do espaço físico tradicional, é o processo de ensino e aprendizagem, mediado por tecnologias, onde professor e aluno estão separados espacial e ou temporalmente.

De acordo com Aretio (1994), a EaD é um sistema tecnológico de comunicação bidirecional que substitui a interação pessoal, em sala de aula, entre professor e aluno, como meio preferencial de ensino, pela ação sistemática e conjunta de diversos recursos didáticos e pelo apoio de uma organização tutorial, de modo a propiciar a aprendizagem autônoma dos estudantes, o autor dita a funcionalidade desta modalidade destacando a importância da mesma para as pessoas que só podem cursar um ensino superior à distância.

A modalidade de ensino em EAD surgiu na segunda metade do século XX, nos Estados Unidos, inicialmente tinha como proposta a utilização de diversos recursos e técnicas de aprendizagem audiovisuais, e destacava a importância do planejamento, organização e controle das atividades e pedagógicas (CAMPOS MAIA, 2007).

A regulação do ensino EAD no Brasil ocorreu a partir do decreto $n^{\circ} 5.622$, de 19 de dezembro de 2005, regulamenta a $\mathrm{EaD}$ como sendo a modalidade educacional na qual a mediação didático-pedagógica nos processos de ensino e aprendizagem ocorre com a utilização de meios e Tecnologias da Informação e Comunicação, com estudantes e professores desenvolvendo atividades educativas em lugares ou tempos diversos. (BRASIL, 2005)

A partir dos anos 2000, a modalidade de ensino EAD, apresentou crescimento vertiginoso, ao mesmo tempo que era alvo de críticas preconceitos que questionavam sua qualidade, na contemporaneidade, devido a pandemia do Covid 19 e a necessidade do isolamento, a educação a distância foi definitivamente incorporada ao cenário educacional no país.

A partir dos anos 2000 a tecnologia iniciou seu processo de enraizamento e fortalecimento da sua presença na sociedade mundial, ela avançou em todas as direções ciência, economia, cultura, saúde, educação etc., duas décadas depois dessa inserção, a tecnologia está presente em $99 \%$ do nosso cotidiano, e não conseguimos mais imaginar o que seria nossas vidas sem os sistemas, aplicativos, e o mundo de possibilidades que a tecnologia nos apresenta.

A adaptação as tecnologias e ao mundo digital, emergiram tanto no ensino público quanto no ensino privado, e essa adaptação só foi possível devido a utilização de 
"videoconferência, redes sociais e até mesmo a adaptação para a modalidade de Educação a Distância (EAD) através da criação de ambientes virtuais de aprendizagem (AVA)." (CORDEIRO, 2020)

Finalmente, a pandemia trouxe para a educação o desafio de reinventar-se, e trouxe à tona problemáticas tais como a valorização do professor, a família e seu papel no processo educativo, a utilização da tecnologia na educação e as iniciativas do poder público para modernização e implantação da educação tecnológica no ensino.

Ressaltamos que a tecnologia é fonte difusora de conhecimentos, libertando o indivíduo das limitações do ambiente social e intelectual, proveniente do ensino tradicional, diante disso, a problemática que envolve a relação ensino e educação tecnológica está inserida na dificuldade dos professores de apropriarem-se e utilizarem adequadamente a tecnologia na prática cotidiana. Esse avanço crescente da tecnologia é o instrumento que media a relação do estudante como o mundo, tendo a necessidade de repensar e atualizar sempre as metodologias de ensino.

A adoção do conceito remoto permitiu prosseguir com o melhor do ensino presencial com as vantagens do ensino virtual. Com isso, muitos desafios para a continuidade da educação mundial surgiram, dentre eles: o uso excessivo da tecnologia e a dificuldade de acesso dos estudantes as Tecnologias Digitais de Informação e Comunicação (TDIC's); além de todas as questões socioemocionais (ANDRADE et al., 2020).

Nesse contexto, professores e alunos adaptaram-se ao ensino remoto, as aulas a distância e deram continuidade as atividades educativas. O modo de ensinar e aprender tiveram que se adaptar abruptamente ao uso das tecnologias educacionais no modelo de ensino e aprendizagem com a utilização das tecnologias professores e estudantes.

Destacamos que apesar da pandemia ter acelerado a inserção das TDIC's na educação, isso não altera a finalidade principal da educação, que é a aprendizagem significativa dos alunos, e nesse processo, existem muitos desafios mais também muitas possibilidades de conduzir os alunos para a construção do conhecimento. (MARCOM E VALLE, 2020)

\section{Docência no Ensino Superior em EaD}

Para Aretio (1994) EaD é um sistema tecnológico de comunicação bidirecional que substitui a interação pessoal, em sala de aula, entre professor e aluno, como meio preferencial de ensino, pela ação sistemática e conjunta de diversos recursos didáticos e pelo apoio de uma organização tutorial, de modo a propiciar a aprendizagem autônoma dos estudantes. 
As análises e considerações do estudo de Vallin (2014) mostra que mesmo Paulo Freire não tendo escrito para a EAD, sem ter conhecido os AVAs, seu pensamento, como a Pedagogia da Autonomia, pode perfeitamente ser usado como base para a EAD.

A EaD vem expandindo muito nos últimos anos através das tecnologias de informação e comunicação não estando limitada por barreiras físicas. Esse crescimento e ampliação devido ao grande número de alunos buscando essa modalidade por apresentar uma série de vantagens que se adequa perfeitamente as pessoas que não puderam em um tempo oportuno cursar uma graduação ou ainda, por falta de oportunidades estudar na idade certa, permitindo estudar em qualquer lugar, dentro da rotina, com controle sobre espaço e tempo evitando o deslocamento.

Para Cordeiro (2020) “O uso adequado e estruturado da tecnologia na Educação, quando aliado ao trabalho docente, pode impulsionar a aprendizagem dos alunos.", afinal, no mundo global a tecnologia permeia todas as áreas e a escola precisa desenvolver nos alunos os conhecimentos e competências necessários para atender as demandas e urgências do mundo contemporâneo.

Com certeza, nesse momento de aprendizado com esta nova modalidade de ensino tende a reforçar ao professor, conhecer as Metodologias Ativas para construção do processo de ensino e aprendizagem, além de promover atualização funcional, promove também um trabalho pedagógico mais ativo e leve para si, para os colegas que compartilham tais desafios e sobretudo aos estudantes, novas práticas pedagógicas de aprendizagem (SILVA, 2018). Alternativas pedagógicas para restabelecer uma aprendizagem mais efetiva, são importantes para que os alunos se tornem participantes ativos no processo de aquisição de conhecimentos (SILUS et al., 2020).

Os grandes desafios enfrentados à prática docente no ensino híbrido é a dificuldade em ensinar e aprender no contexto de sala de aula, pois no nesse modelo de ensino, os alunos são estimulados a desenvolver competências, habilidades e hábitos de estudo, no tempo definido por eles, preparando-se para a vida profissional (DE CAMPOS MAIA, 2007).

Essas diferentes metodologias de ensino são desafiadoras para os professores, podendo apresentar resistência nas formações docentes. Outro fator desafiador é a velocidade com que as tecnologias se atualizam, tornando mais difícil esse acompanhamento dos docentes. As formações e capacitações para os professores se ambientarem e familiarizarem com as ferramentas tecnológicas devem ser constantes (WEBER; DE ASSIS OLGIN, 2020).

Na modalidade de ensino a distância, o professor desempenha o papel de facilitador do processo de aprendizagem, orientando os alunos quanto à aquisição de conhecimentos e habilidades cognitivas (SILVA et al., 2020). 
Destacamos que é urgente pensar na formação docente em EaD, pois a formação de educadores implica em pensar sobre modelos e atitudes que esses profissionais devem desempenhar. Lima destaca ainda que a formação do professor não é acumular conhecimentos e sim saber aplicá-los, questioná-los, revê-los e modificá-los para a realidade da sala de aula em termos de nível de desenvolvimento dos alunos. No processo de formação do docente não basta identificar a formação do professor como um problema, é necessário pensar e operacionalizar ações efetivas que solucionem essa questão. (LIMA,1998)

O sucesso na implementação de uma prática pedagógica híbrida no ensino superior é dependente de um trabalho coletivo que envolve a participação de gestores, docentes e discentes. É necessário que a universidade proporcione um ambiente favorável que possibilite recursos para que haja uma adaptação para esse modelo curricular. Toda prática de ensino-aprendizagem pode ser melhorada, ajustada e inovada e quem não se reinventar estará fora do mercado.

Abordar a problemática da aprendizagem a partir do uso da tecnologia no processo educativo, é um desafio tanto para educadores quanto para alunos, essa dificuldade reside na dificuldade de identificar parâmetros para definir quais os recursos tecnológicos podem ser utilizados no contexto de ensino aprendizagem.

A utilização dos recursos tecnológicos no ensino a distância, tem como finalidade possibilitar a digitalização de informações ou a produção de conhecimentos digitais, dessa forma, a interação é essencial na $\mathrm{EaD}$ e as tecnologias digitais são as ferramentas que potencializam a interação. Schelesky (2020), chama atenção para a necessidade de se estabelecer uma identificação cultural com as tecnologias, além de conhecer e compreender seus funcionamentos e limitações.

O ensino EAD contribui para a socialização das diferentes linguagens, saberes docentes e discentes. Como "canal" direto de comunicação entre professores-tutores e alunos, que estão distantes fisicamente, mas próximos por meio da "dialogia digital", ela requer atenção redobrada tanto do aluno como do professor, contribuindo para melhoria na qualidade da aprendizagem, dos vínculos estabelecidos e das relações de ensino e aprendizagem.

Martins (2006) explica que a construção do conhecimento demandado, então, apreensão do conteúdo, prenhe de mediações históricas concretas que só podem ser reconhecidas à luz das abstrações do pensamento, isto é, do pensamento teórico. Não se trata de descartar a forma pela qual o dado se manifesta, pelo contrário, trata-se de sabê-la com dimensão parcial, superficial e periférica do mesmo. Portanto, o conhecimento calcado na superação da aparência em direção à essência requer a descoberta das tensões imanentes na inter vinculação e interdependência 
entre forma e conteúdo. Ótimas colocações do autor. É pertinente citar que o conhecimento partirá sempre de um desejo, o desejo de conhecer mais, se inteirar de determinando assunto.

Peters (2009) afirma que existem muitos docentes que estão convencidos de que a única diferença entre o ensino presencial e o EAD, é apenas a "distância" e a importância da mídia técnica necessária para transpor o abismo entre quem ensina e quem aprende, pois defendem que o processo de ensino-aprendizagem permanece idêntico. Constata-se assim que ainda existem muitos caminhos a serem percorridos pelo ensino $\mathrm{EaD}$, e um dos mais urgentes diz respeito quanto a sua funcionalidade e organização, pois as diferenças vão para além do formato e da mídia tecnológica, eles perpassam pelo planejamento, organização e acompanhamento do progresso do aluno.

Cabe ao docente o desafio de buscar o equilíbrio entre informações em excesso para que os alunos não se sintam desestimulado e alimentar as novas informações em determinados períodos para que os estudos se tornem enriquecidos e atualizados. A relação educativa dependerá da ação do docente acompanhando as buscas e descobertas, e não somente avaliando os resultados.

Ainda com base no trabalho docente em EaD, Belloni (2008) acrescenta que o trabalho do professor em $\mathrm{EaD}$ deve ser reconhecido igualmente ao do professor presencial, os dois assumem uma função necessária e relevante no contexto educacional.

Sobre a docência no ensino Ead, Neves e Fidalgo, (2008) afirmam que o discurso da flexibilidade, da autonomia e do trabalho fácil é, muitas vezes, enganoso e evidencia-se como sobrecarga de trabalho, com número elevado de alunos e demandas por conhecimentos/competências que ele ainda não domina. Há ainda a questão (da possibilidade) de controle excessivo do processo de produção e execução do trabalho. É importante que o ensino em EaD veja os pormenores de cada situação. Acompanhar os estudantes e verificar o nível de aprendizagem é essencial em EaD.

Para Aretio (1994), a diferença no grau de separação de professor e aluno em uma e outra forma de ensinar tem raiz no próprio desenho do processo ensino-aprendizagem, pois nos sistemas presenciais, este desenho está fundamentado na relação direta cara a cara de professores e alunos, geralmente produzida em aula real. Enquanto nos sistemas de educação a distância, a relação professora aluno difere no tempo e no espaço e que a aprendizagem está baseada na autonomia do aluno, nos materiais elaborados para esse modelo de ensino, e na consciência de que o docente não estará necessariamente no mesmo lugar físico que o aluno.

Finalmente destacamos que o ensino a distância, as TIC'S, os recursos tecnológicos e os meios audiovisuais transformaram o professor em um facilitador da aprendizagem dos alunos,

762 Id on Line Rev. Mult. Psic. V.15, N. 55, p. 755-768, Maio/2021 - ISSN 1981-1179

Edição eletrônica em http://idonline.emnuvens.com.br/id 
cabe a ele guiar o aluno em meio às dificuldades da construção do conhecimento na sociedade contemporânea. Mais do que repassar conteúdos, cabe ao professor do Ead estimular a autonomia dos alunos na aprendizagem e construção do conhecimento.

\section{Pandemia da Covid 19 e Aprendizagem à Distância}

Segundo dados da Organização das Nações Unidas para a Educação, a Ciência e a Cultura (UNESCO, 2020), mais de 1,5 bilhão de estudantes de 191 países estão sendo afetados pelo fechamento das escolas e universidades. Pode-se perceber que nesse período de pandemia houve uma readaptação da aprendizagem mediada por tecnologia foi necessário mudar a didática de ensino nesse novo cenário. Dessa forma, o que se observa é uma necessidade de adaptabilidade do uso das tecnologias educacionais no modelo de ensino e aprendizagem.

A pandemia do coronavírus, em 2020, afetou 1,3 bilhão de estudantes em todo o mundo. Com isso, o número de aulas suspensas, só no Brasil foram de 57 milhões. O fechamento de universidades forçou as instituições do ensino superior a acelerarem o processo de transformação digital que levariam anos para ganharem escala com a implementação de metodologias digitais (ZEDNIK, 2020).

Algumas medidas de contenção da transmissão do vírus, foram pensadas e divulgadas para conhecimento de todos, o isolamento e quarentena.

De acordo com a Lei Brasileira 13.979\2020, em seu art. $2^{\circ}$ destaca:

I- Isolamento: separação de pessoas doentes ou contaminadas, ou de bagagens, meios de transporte, mercadorias ou encomendas postais afetadas, de outros, de maneira a evitar a contaminação ou a propagação do corona vírus;

II - Quarentena: restrição de atividades ou separação de pessoas suspeitas de contaminação das pessoas que não estejam doentes, ou de bagagens, contêineres, animais, meios de transporte ou mercadorias suspeitos de contaminação, de maneira a evitar a possível contaminação ou a propagação do coronavírus.

A conforme (LIN, PENG \& TSAI, 2010 IN HOLANDA. 2020) (OMS) a quarentena é uma medida comprovadamente eficaz contra a disseminação do vírus e contribui para a diminuição de novos casos. Medidas estas que foram tomadas com o intuito de salvar vidas.

Abordar a problemática da aprendizagem a partir do uso da tecnologia no processo educativo, é um desafio tanto para educadores quanto para alunos, pois cada um exerce seu papel com foco na construção da aprendizagem dos alunos, a participação do aluno na aula, possibilitando assim espaços cada vez mais interativos. Essas dificuldades residem em identificar parâmetros para definir quais os recursos tecnológicos podem ser utilizados no 
contexto de ensino aprendizagem. O conhecimento do mundo virtual fará com que os alunos busquem explorando todo o material disponível ampliem o seu conhecimento de forma interativa (WEBER; DE ASSIS OLGIN, 2020).

Resultados apontam que há uma perda de desempenho maior entre estudantes de baixa renda, pois além da deficiência de acesso às tecnologias tendem a sofrerem mais os impactos emocionais da crise financeira causada pela pandemia, podendo fazer com que não tenham mais acesso ao mundo virtual. Eles também são apresentam mais alterações emocionais e estão menos propensos a ter em casa um ambiente de aprendizado adequado, como espaço silencioso, o que fundamental para um aprendizado agradável e eficiente. Outro resultado apresentado é a desigualdade de acesso à internet banda larga nos domicílios, nas diversas regiões brasileiras. Ainda há domicílios e localidade que não estão incluídas na era tecnológica (CARDOSO; FERREIRA; BARBOSA, 2020).

O ano de 2020, apresentou um cenário mundial transformado pela pandemia de COVID 19, diante disso todos os setores da sociedade foram acometidos pela urgência de adaptar-se à nova realidade da quarentena, essa adaptação das atividades, econômicas, culturais, educacionais e sociais só foi possível, devido aos avanços da tecnologia no âmbito das comunicações e informação.

A pandemia de Covid19, traz à tona a discussão sobre a urgência de mecanismos para a implementação da educação a distância em nosso país e fez emergir a consciência da contribuição da tecnologia e dos profissionais que a utilizam para a humanidade, com a educação não foi diferente, e trouxe à tona a urgência da implementação do ensino a distância no Brasil. Pois no âmbito educacional, as instituições de ensino mergulharam fundo nas possibilidades de uso tecnológico e reinventaram-se a partir dos aparatos digitais.

Segundo Santos Colvara e Espírito Santo (2019), a falta de competência digital também apresenta grande dificuldade para os estudantes que não apresentam a fluência digital exigida para os estudos nos diversos cenários virtuais de aprendizagem. Sabendo que no Ensino Híbrido o estudante possui a responsabilidade da aprendizagem e dessa forma, necessita ser o protagonista na sala de aula, desenvolvendo projetos, resolvendo problemas, criando oportunidades para a construção de seu próprio conhecimento. O docente fica com a função de mediador e de consultor do estudante que busca aprender.

$\mathrm{O}$ impacto da pandemia na educação favoreceu esse momento de derrubar alguns preconceitos existentes e mostrar que a modalidade de EAD está devidamente pronta para as mudanças na educação e que pode ser tão eficaz no aprendizado do aluno quanto o ensino presencial, se aplicada da maneira adequada. Esse conhecimento veio de forma ampla, para

764 Id on Line Rev. Mult. Psic. V.15, N. 55, p. 755-768, Maio/2021 - ISSN 1981-1179

Edição eletrônica em http://idonline.emnuvens.com.br/id 
docentes, discentes e corpo dirigente das IES propondo análises, considerações e reflexões entre os educadores objetivando estratégias para o processo de aprendizagem também nos cursos presenciais com metodologias já usadas pela $\mathrm{EaD}$, ajudando a quebrar esses paradigmas institucional e ressignificando os conceitos de distância e de ensino.

A pandemia transformou de forma inesperada as instituições de ensino, transformou as práticas e os métodos pedagógicos, a primeira vista foi uma mudança assustadora no entanto a longo prazo revela-se positiva, pois trouxe modificações nos modelos pedagógicos. Dentre os ganhos pedagógicos podemos destacar uma reestruturação dos métodos, referenciais e critérios avaliativos; além da inserção dos recursos tecnológicos no processo de ensino e aprendizagem remota, proporcionou a construção de uma rede de compartilhamento de experiencias de ensino entre educadores de todo o país, sem falar na conscientização da aprendizagem contínua dos docentes e principalmente ter consciência de que as aulas online não são a mesma coisa que as aulas presencial. (SILVA, 2020).

\section{Considerações Finais}

Ao final desse estudo concluímos que a relevância da discussão e reflexão sobre os desafios da educação a distância durante a pandemia do Covid 19, foram responsáveis pela quebra de paradigmas e preconceitos contra essa modalidade de ensino, ao mesmo tempo que alertou para a urgência da formação de professores preparados para a utilização das TIC's.

Dessa forma, apresentamos algumas considerações com relação ao ensino remoto no Brasil, o trabalho docente e o contexto pandêmico.

Confrontada com desafios cada vez mais complexos decorrentes nos últimos anos, a $\mathrm{EaD}$ tem mostrado que veio para ficar e fazer parte da vida das pessoas que desejavam cursar um ensino superior e, que por inúmeras razões não puderam, ao mesmo tempo que chamou a atenção para a necessidade de maiores investimentos na área de TICs e na formação docente.

Com a realização deste trabalho ficou evidenciado a importância do ensino em EaD no Brasil. Desejamos que o nosso país se desenvolva em várias áreas, mas em conhecimento é o nosso maior desejo. Sabe-se que a base do desenvolvimento de uma nação é a Educação, para isto acontecer é necessário dar oportunidades a todos, e vemos que o ensino a distância veio para promover isto.

Podemos tecer ainda, como considerações que o cenário pandêmico que tem afetado a todos seguimentos, afetou também a educação, levando instituições de ensino superior a 
utilizarem cada vez mais as TICs ao mesmo tempo que substitui as tradicionais habilidades acadêmicas por metodologias inovadoras e habilidades necessárias para a formação de profissionais de excelência.

Assim, os assuntos pesquisados aqui nos fizeram pensar na relevância da educação a distância, o trabalho docente remoto, o contexto pandêmico e a aprendizagem no país. Procuramos ainda, apresentar estes elementos porque consideramos essenciais nos dias de hoje.

Dessa forma, é importante destacar o histórico da EaD no Brasil, antes criticado e hoje reconhecido pelos avanços no campo educacional, o que tem incentivado investimentos nesta área promissora. Afinal a EAD proporciona oportunidades de aprendizagem e formação tanto para jovens quanto para profissionais que desejam se aperfeiçoar ou se profissionalizar em uma nova área de conhecimento.

Espera-se que as informações contidas neste artigo possam interessar aos leitores e a partir da leitura ousem a dar continuidade a esta pesquisa que consideramos essencial no contexto educacional, esperamos ainda, que estes assuntos possam contribuir para a realização de novas pesquisas e estudos aprofundados sobre o tema.

\section{Referências}

ALTHAUS, M. T. M. Ação didática no ensino superior: a docência em discussão. Revista Teoria e Prática da educação, v. 7, n. 1, p. 101-106, 2004.

BELLONI, Maria Luiza. Evucação a Divtância. 3. ed. Campinas: Autores Associados, 2008.

BRASIL. Lei $n^{0}$ 9.394, de 20 de dezembro de 1996. Estabelece as diretrizes e bases da educação nacional. Diário Oficial da União, Brasília, 1996.

DA SILVA PESSOA, Tatiane de Fatima; DOS SANTOS, Eliane Aparecida Galvão; ALVES, Marcos Alexandre. Reflexões sobre as práticas pedagógicas no ensino superior em período de pandemia. Disciplinarum Scientia| Ciências Humanas, v. 21, n. 2, p. 119-132, 2020.

DE ANDRADE C. L. et al. Uso de tecnologias no ensino superior público brasileiro em tempos de pandemia COVID-19. Research, Society and Development, v. 9, n. 8, p. e267985485e267985485, 2020.

DE CAMPOS MAIA, Marta. Educação a distância. GV Executivo, v. 6, n. 5, p. 56-60, 2007.

DOS SANTOS C., J.; DO ESPIRITO SANTO, . Metodologias ativas no ensino superior: o hibridismo da sala de aula invertida. Revista Brasileira de Aprendizagem Aberta e a Distância, v. 18, n. 1, p. 19-19, 2019. 
DA SILVA, J. F. Didática no Ensino Superior: estratégias de ensino adequadas à arte de ensinar. Educação Por Escrito, v. 9, n. 2, p. 204-219, 2018.

CARDOSO, C. A; FERREIRA, V. A.; BARBOSA, F. C. G. (Des) igualdade de acesso à educação em tempos de pandemia: uma análise do acesso às tecnologias e das alternativas de ensino remoto. Revista Com Censo: Estudos Educacionais do Distrito Federal, v. 7, n. 3, p. 38-46, 2020.

CORDEIRO, K. M. A . O Impacto da Pandemia na Educação: A Utilização da Tecnologia como Ferramenta de Ensino. 2020.

CORRÊA, Carlos Eduardo Ferla et al. TECNOLOGIA E EDUCAÇÃO: UMA RELAÇÃO DEMOCRÁTICA? Revista Mundi Engenharia, Tecnologia e Gestão, v. 5, n. 3, 2020.

FERREIRA, Giselle M. dos S.; ROSADO, Luiz Alexandre da S.; CARVALHO, Jaciara de S. Educação e Tecnologia: abordagens críticas. Rio de Janeiro: SESES, 2017.

LIN, E. C. L.; PENG, Y. C.; TSAI, J. C. H. J. A. j. o. i. c. Lessons learned from the antiSARS quarantine experience in a hospital-based fever screening station in Taiwan. $38, \mathrm{n}$. 4, p. 302-307, 2010.

LIMA, Claudia Maria. Ensino a Distância e professores: formas de apropriação em educação contínua. [s.l.]: [s.n.], 1998.

MARTINS, Ronei Ximenes. A covid-19 e o fim da educação a distância: um ensaio. EmRedeRevista de Educação a Distância, v. 7, n. 1, p. 242-256, 2020.

MARTINS, Ligia. As aparências enganam: divergências entre o materialismo histórico dialético e as abordagens qualitativas de pesquisa. In: Reunião Anual ANPED, 29., 2006, Rio de Janeiro. Anais... Rio de Janeiro: Anped, 2006.

NEVES, Viana de Salles Inaja; FIDALGO, Fernando Selmar. Docente virtual na Educação a Distância: condições de trabalho na rede privada de ensino. In: I Seminário Nacional de Educação Profissional e Tecnológica, SENEPT. Belo Horizonte: CEFET-MG, 2008, v. 1.

ORGANIZAÇAO DAS NAÇÕES UNIDAS PARA A EDUCAÇÃO, A CIÊNCIA E A CULTURA -UNESCO. Metade dos alunos fora da escola não tem computador em casa. 2020.

PAVANELO, Elisangela et al. Contribuições para Preparação do Professor na Educação a Distância. Revista Brasileira de Aprendizagem Aberta e a Distância, v. 17, n. 1, 2018.

PETERS, Otto. A Educação a Distância em transição. São Leopoldo: Unisinos, 2009.

SANTOS, Fábio Maurício Fonseca; ALVES, André Luiz; PORTO, Cristiane de Magalhães. Educação e Tecnologias. Revista Científica da FASETE, p. 44, 2018. 
SILVA, B. S. F et al. Prática Pedagógica Híbrida no Ensino Superior em Tempos de Pandemia por Sars-Cov-2: Análise Crítica da Literatura. Anais do Seminário de Atualização de Práticas Docentes, v. 2, n. 1, 2020.

SILUS, A et al. Desafios do ensino superior brasileiro em tempos de pandemia da COVID-19: repensando a prática docente. Liinc em Revista, v. 16, n. 2, p. e5336-e5336, 2020.

SCHELESKY, P. S., et al. Formação de professores EaD e a relação com o uso da tecnologia: uma análise a partir de professores egressos. 2020.

TEIXEIRA, Anísio. Mestres de amanhã. Revista Brasileira de Estudos Pedagógicos, Rio de Janeiro, v. 40, n. 92, p. 10-19, out./dez. 1963.

VALLIN, Celso. Educação a distância e Paulo Freire. Revista Brasileira de Aprendizagem Aberta e a Distância, v. 13, 2014.

WEBER, E. L.; DE ASSIS O. Metodologia de ensino híbrido no ensino superior: uma revisão da literatura. In: Anais do CIET: EnPED: 2020-(Congresso Internacional de Educação e Tecnologias| Encontro de Pesquisadores em Educação a Distância). 2020.

ZEDNIK, H. Taxonomia das Tecnologias digitais na Educação. Aporte à cultura digital na sala de aula. Sobral: Sertão Cult, 2020.

\section{Como citar este artigo (Formato ABNT):}

MENDES, Josiane Lima; PONTE, Eliza Angélica Rodrigues; SOUSA, Léa Barbosa de; SAMPAIO, Cynira Kezia Rodrigues Ponte; PONTE, Nayara Machado Melo. Educação à Distância e Docência no Ensino Superior: Mudança de Paradigma Através da Utilização das Tecnologias no Processo de Ensino e Aprendizagem em Tempos de Pandemia da Covid 19. Id on Line Rev.Mult. Psic., Maio/2021, vol.15, n.55, p. 755-768, ISSN:1981-1179.

Recebido: 19/05/2021

Aceito: 29/05/2021 